\author{
Military Technical College \\ Kobry El-Kobbah, \\ Cairo, Egypt
}

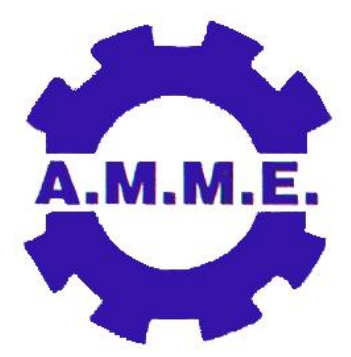

14th International Conference on Applied Mechanics and Mechanical Engineering.

\title{
Modeling of Hydro-gas Unit for Ground Vehicles Suspension
}

\author{
By \\ H.A.Hammad, I.A.Elsherif, A.M.Salem, A.M.Zidan *
}

\section{ABSTRACT:}

Nowadays, the hydro-gas suspension unit is currently used as a part of suspension system of modern vehicles. This paper aims to evaluate the working characteristics of hydro-gas suspension unit.

The theoretical study includes modeling of the hydro gas suspension unit and validation of the developed model using MATLAB/SIMULINK. The experimental measurements are carried out to validate the results obtained from simulation. The unit force, created inside the hydro gas unit during its action, includes the elastic and damping forces and Variation of these forces with displacement and velocity of moving part. This variation is used as input parameters in the equation of oscillation of vehicle hull to study its vibrational response.

The obtained results show that the unit force depends mainly on the displacement and velocity of moving parts of hydro-gas unit. In addition, the results show that the effect of amplitude and frequency at small working range has a negligible influence on the unit force. 


\section{${ }^{\star}$ Egyptian Armed Forces}

\section{Introduction:}

One of the most important demands imposed on modern military vehicles is to improve the smoothness of their movement. This demand is in connection with the effort to increase the vehicle mobility, especially during off road operation, and beside the precise fire on move. The smoothness of tracked vehicles drive depends mainly on the type and quality of vehicle suspension system [1]. Therefore, it is necessary to identify the characteristics of suspension elastic element under real conditions [2].

High-mobility military vehicles, such as battle tanks and armored personnel carriers (APC), are designed for drive over rough terrain surfaces. The mobility performance of these vehicles is often limited by the operator's endurance and components capabilities to withstand the transmitted shocks and vibrations. With a continual demand of increased power to weight ratio and higher speeds, the present trend is toward the use of advanced suspension systems such as hydro-gas or hydro pneumatic suspension. This tends to be lighter and more compact; can be mounted out side the hull, incorporate integral damping arrangements, and offer load-leveling capabilities due to their non-linear progressively stiffening spring characteristics [3].

In order to design some vibration isolator or shock absorber for the dual demand of resisting violent impact and vibration, the accurate characterization of the shock absorber is of paramount importance. Indeed, the characterization makes it possible to define a sufficiently precise mathematical model of a shock absorber or vibration isolator for design purpose [3].

\section{Modeling of hydro-gas suspension unit:}

Figure (1) shows a functional scheme of the studied hydro gas suspension unit, the coordinate $X$ represents the displacement of piston while $Z$ coordinate represents the displacement of the moving rod.

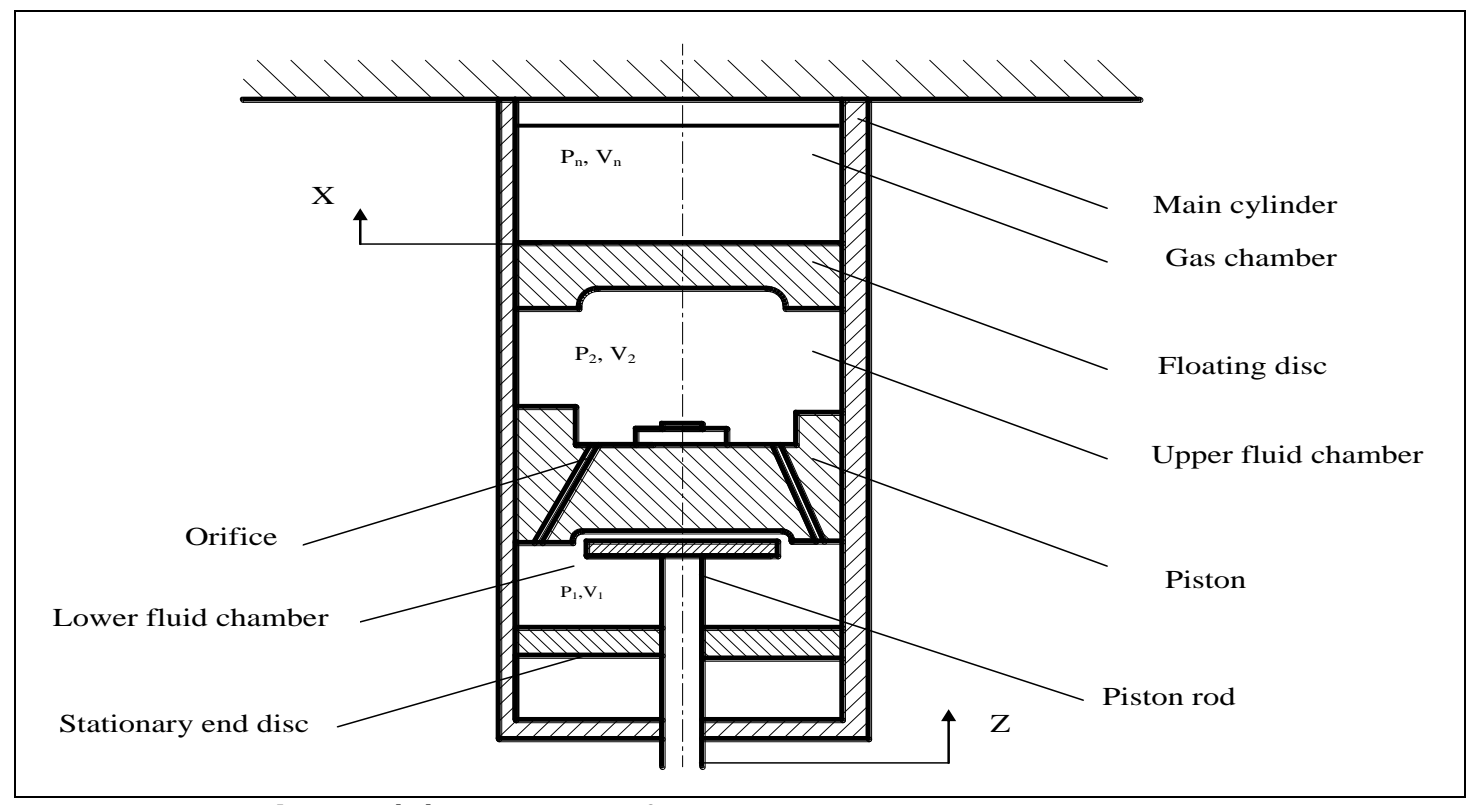

Figure (1): scheme of the hydro gas suspension unit. 
The mathematical model is developed by deriving the equations describing the dynamic behavior of suspension unit.

The following assumptions were considered for developing the mathematical model:

1- The density and bulk's modulus of oil are constant.

2- Coefficient of discharge (Cd) is assumed constant.

3- The variation of the viscosity of oil is neglected.

4- Negligible leakage flow rate.

5- Polytropic process for the gas compression and expansion.

\subsection{Fundamental equations:}

The flow rate through the orifices of hydro gas unit is given by the following equation:

$$
Q=C_{d} \quad A_{O} \sqrt{\frac{2\left(P_{2}-P_{1}\right)}{\rho}}
$$

While, the Continuity equation in upper chamber is expressed by:

$$
\begin{aligned}
A_{p} & \frac{d Z}{d t}=2 Q+A_{f} \frac{d X}{d t}+\left(\left(V_{2}-A_{p} Z+A_{f} X\right) / \beta\right) \frac{d P_{2}}{d t} \\
& A_{p} \frac{d Z}{d t}-2 Q-A_{f} \frac{d X}{d t}-\left(\left(V_{2}-A_{p} Z+A_{f} X\right) / \beta\right) \frac{d P_{2}}{d t}=0
\end{aligned}
$$

The Continuity equation in lower chamber can be expressed by:

$$
\begin{aligned}
2 Q & =\left(A_{p}-A_{r}\right) \frac{d Z}{d t}+\left(\left(V_{1}+\left(A_{p}-A_{r}\right) Z\right) / \beta\right) \frac{d P_{1}}{d t} \\
& 2 Q-\left(A_{p}-A_{r}\right) \frac{d Z}{d t}-\left(\left(V_{1}+\left(A_{p}-A_{r}\right) Z\right) / \beta\right) \frac{d P_{1}}{d t}=0
\end{aligned}
$$

The equation of motion describes the floating piston movement is:

$$
m_{f} \frac{d^{2} X}{d t^{2}}=\left(P_{2}-P_{g}\right) A_{f}-m_{f} g-f_{f} \frac{d X}{d t}
$$

The volume of the nitrogen gas inside the chamber is given by:

$$
V_{g}=V_{O}-A_{f} X
$$

Therefore, the nitrogen gas pressure is determined from the equation

$$
P_{o} V_{o}^{1.35}=P_{g} V_{g}^{1.35}
$$

Equation of motion of piston is represented by:

$$
m_{p} \frac{d^{2} Z}{d t^{2}}=P_{1}\left(A_{p}-A_{r}\right)-P_{2} A_{p}-C_{V} \frac{d Z}{d t}
$$

The parameters of the hydro gas suspension unit model are as follows:

$A_{o}=2.009^{*} 10^{-6} \mathrm{~m}^{2}, C_{d}=0.65, \rho=850 \mathrm{~kg} / \mathrm{m}^{3}, A_{p}=1.0178^{*} 10^{-3} \mathrm{~m}^{2}, A_{f}=9.621^{*} 10^{-4}, \beta=1.3^{*} 10^{9} \mathrm{pa}$, $m_{\mathrm{f}}=0.055 \mathrm{~kg}, \quad m_{\mathrm{p}}=0.05 \mathrm{~kg}, \quad A_{\mathrm{r}}=9.5^{*} 10^{-5} \mathrm{~m}^{2}, \quad P_{\mathrm{o}}=2 \mathrm{Mpa}, \quad V_{\mathrm{o}}=20.4^{*} 10^{-5} \mathrm{~m}^{3}, \quad \mathrm{f}_{\mathrm{f}}=0.3 \mathrm{Ns} / \mathrm{m}$, $\mathrm{C}_{\mathrm{v}}=0.25 \mathrm{Ns} / \mathrm{m}$. 
The previous equations were by using simulink program in MATLAB7.The input parameters of this program are the displacement and the velocity of the moving part. Figure (2) shows the main page of the hydro gas suspension unit simulink program.

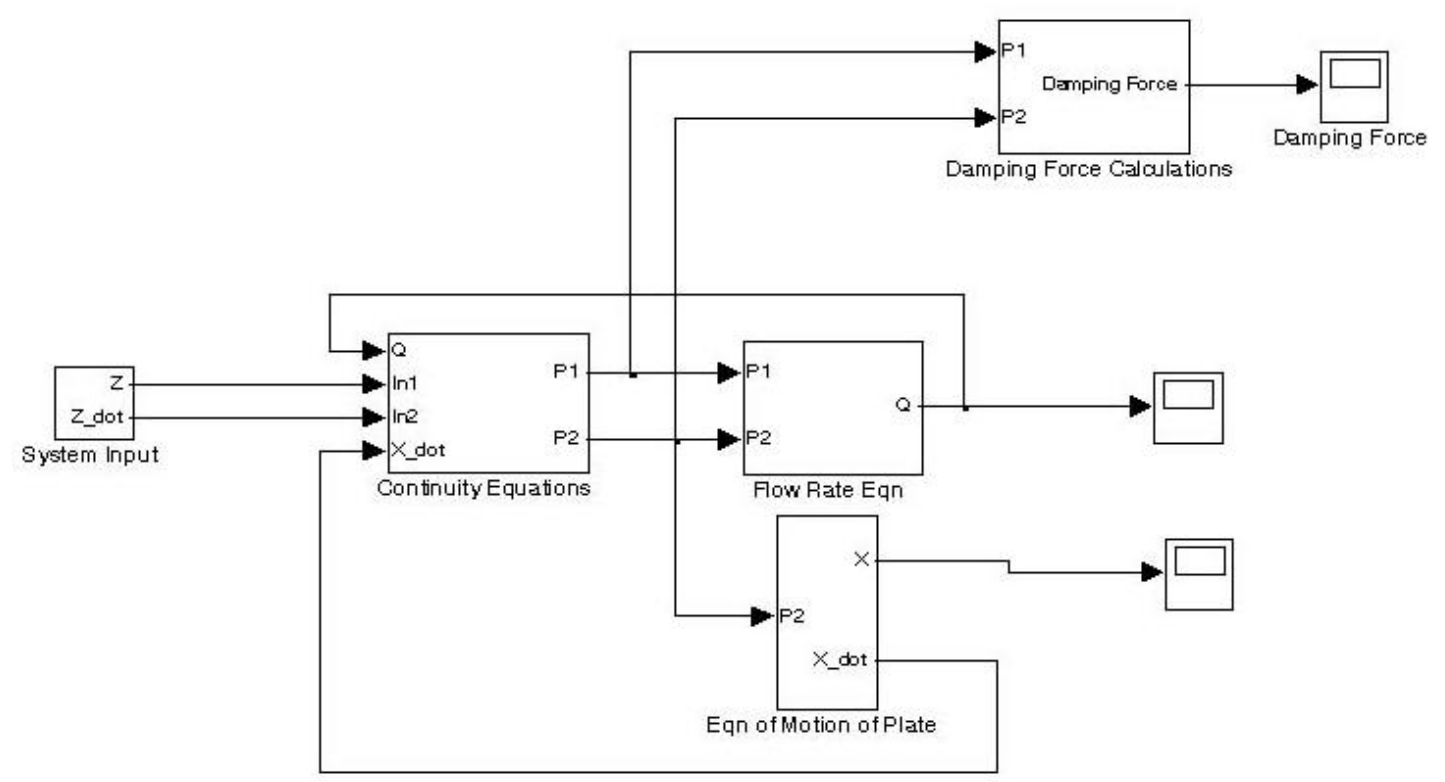

Figure (2): The main page of the shock absorber simulink program

\section{Experimental investigation:}

The shock absorber dynamic characteristics are evaluated experimentally by measuring the hydro gas suspension unit force versus displacement and velocity. The damper test system type 850 MTS shown in figure (3) is used to measure these parameters. The HSU is subjected to input displacement in the form of sinusoidal signal, with different amplitudes and frequencies representing the road configuration. 


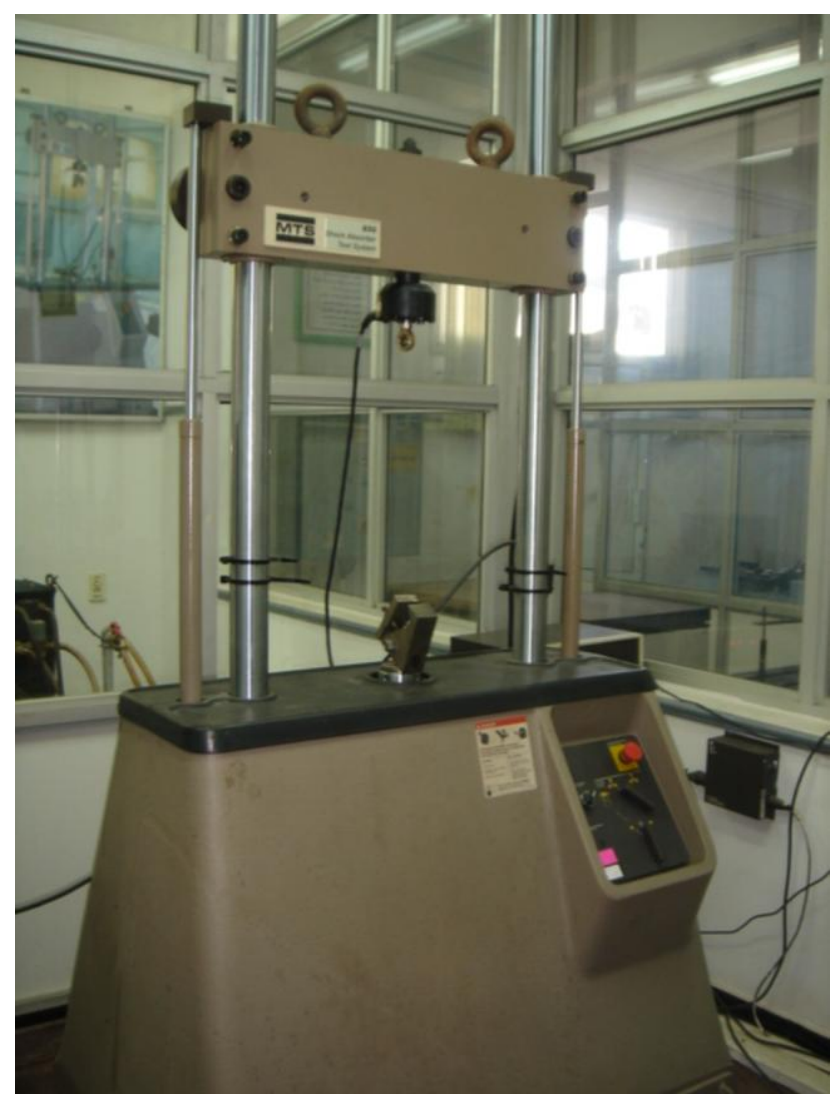

Figure (3): test rig used to identify HSU characteristics

\subsection{Test results:}

The experimental results are shown in figures (4-7), the figures show the variation of the HSU force with the piston velocity and displacement at different frequencies and amplitudes. The amplitude of sinusoidal excitation was varied to be $(40,60,80,100,120)$ $\mathrm{mm}$ while the frequencies of excitation is changed to be $(0.5,1,1.5,2,2.5,3,4) \mathrm{Hz}$. The figures illustrated the test results at $(60,100) \mathrm{mm}$ amplitudes and $(1,2) \mathrm{Hz}$ of frequency.

\subsection{Effect of excitation frequency:}

Figure (4) shows the variation of hydro gas suspension unit force with velocity at different frequencies and at amplitudes $(60,100) \mathrm{mm}$ while figure (5) shows the variation of hydro gas suspension unit force with displacement.

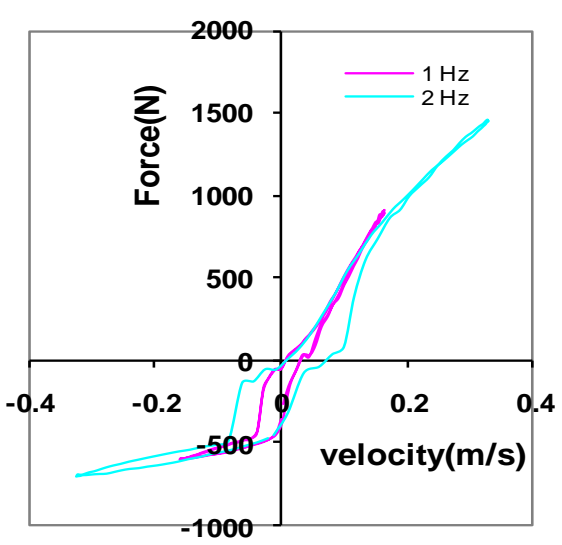

a) $60 \mathrm{~mm}$ amplitude

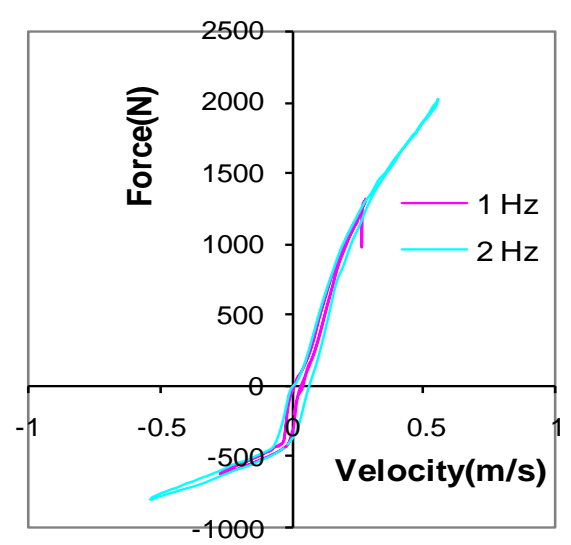

b) $100 \mathrm{~mm}$ amplitude

Figure (4): Variation of HSU force with velocity at different frequencies. 


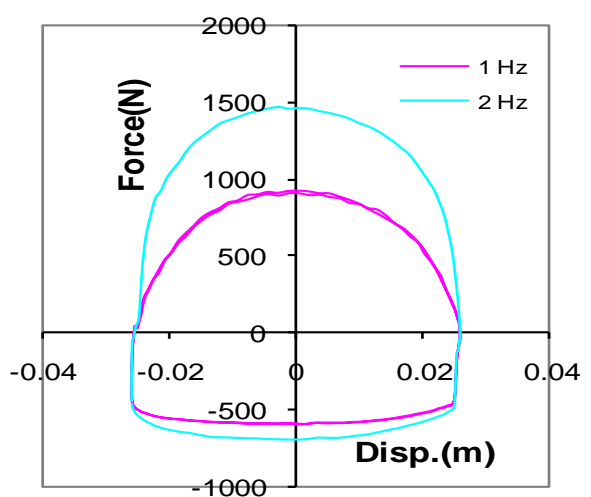

a) $60 \mathrm{~mm}$ amplitude

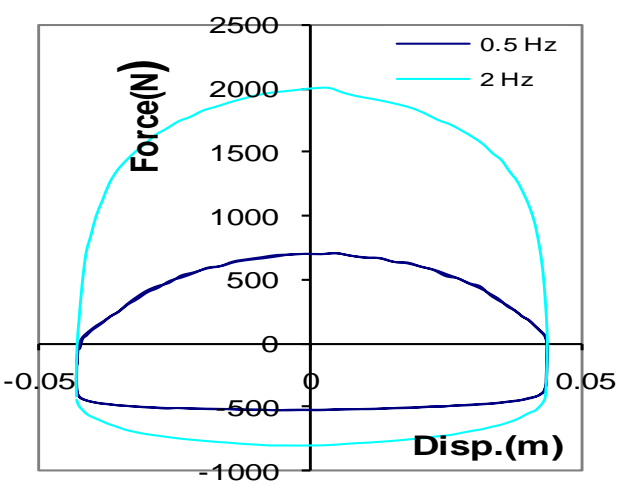

b) $100 \mathrm{~mm}$ amplitude

Figure (5): variation of HSU force with displacement at different frequencies.

\subsection{Effect of excitation amplitude:}

Figure (6) illustrates the variation of hydro gas suspension unit force with velocity at different amplitudes and at frequencies $(1,2) \mathrm{Hz}$ while figure $(7)$ shows the variation of hydro gas suspension unit force with displacement.

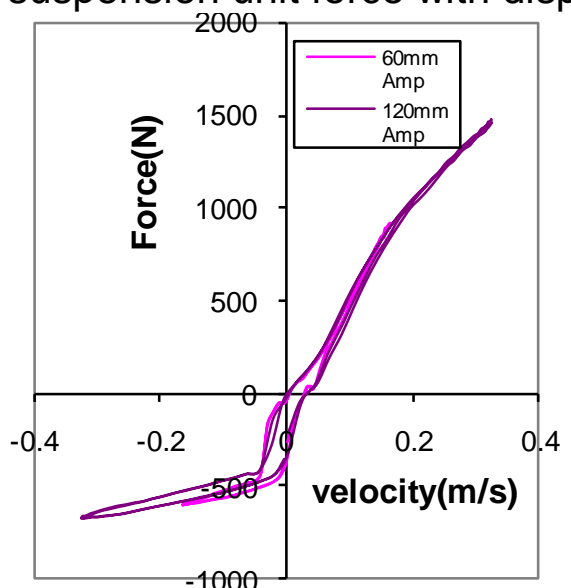

a) $1 \mathrm{~Hz}$

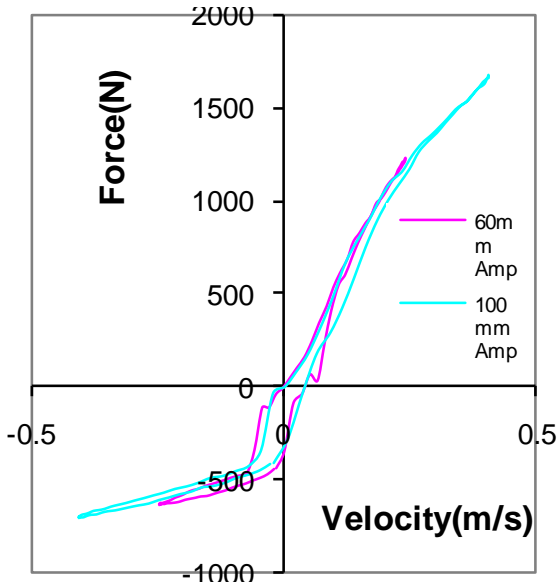

b) $2 \mathrm{~Hz}$

Figure (6): change of HSU force with velocity at different amplitudes.

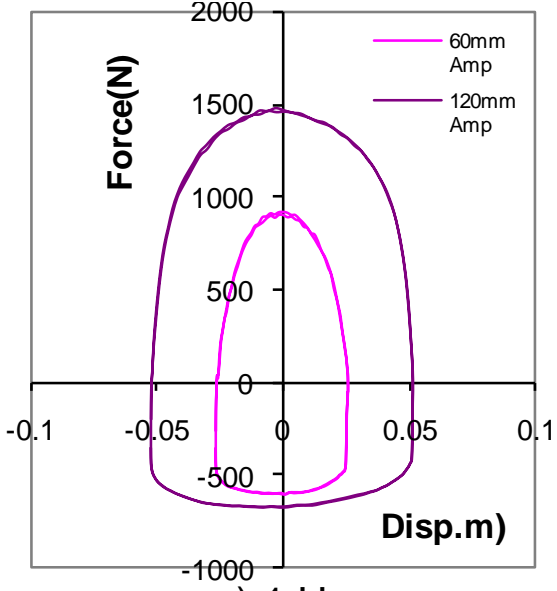

a) $1 \mathrm{~Hz}$

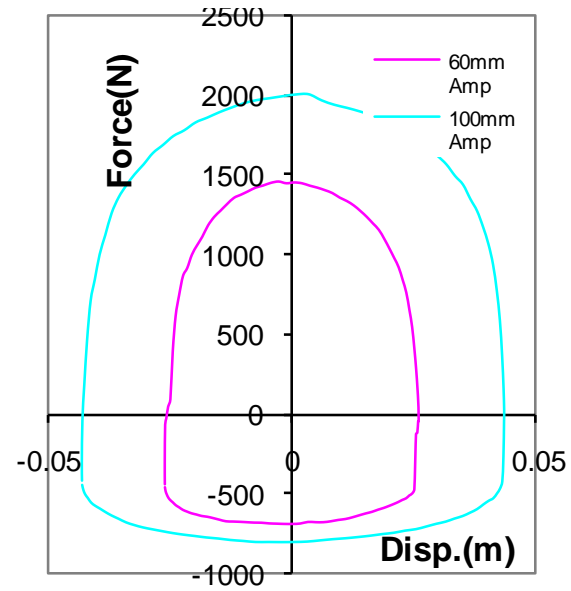

b) $2 \mathrm{~Hz}$

Figure (7): change of HSU force with displacement at different amplitudes.

From the test results, it can be seen that: 
- During the compression stroke, the HSU generates lower damping force in comparison with the generated damping force in the rebound stroke.

- The maximum damping forces in the rebound and compression strokes were found at the middle of unit stroke.

- It is found that for a low frequency range $(0.5$ to $4 \mathrm{~Hz})$, the influence of the amplitude and frequency on the hydro gas suspension unit force is very little so, it can be neglected and the relations between the HSU force and the velocity have non-linear form.

- The hydro gas suspension unit force - velocity relation is nonlinear during rebound and compression strokes. Consequently, the damping coefficient is not constant.

\section{Comparison between the experimental and simulation results:}

Figure (8) show the variation of HSU with piston velocity, time and piston displacement respectively. By comparing the experimental results with the numerical simulation results, it can be seen that there is quite agreement between the two results so; the numerical simulation can be applied to describe the actual characteristics of the HSU.

On the other side, the little distortion in simulation results may be due to the fact that the program not simulates accurately the compressibility effect of the hydraulic oil.

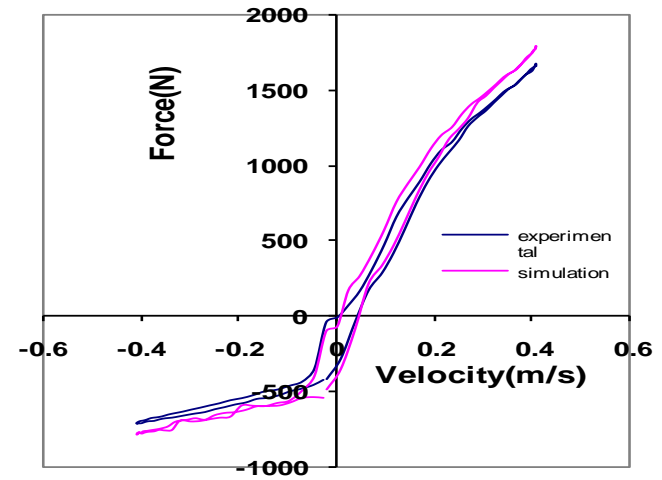

(a)

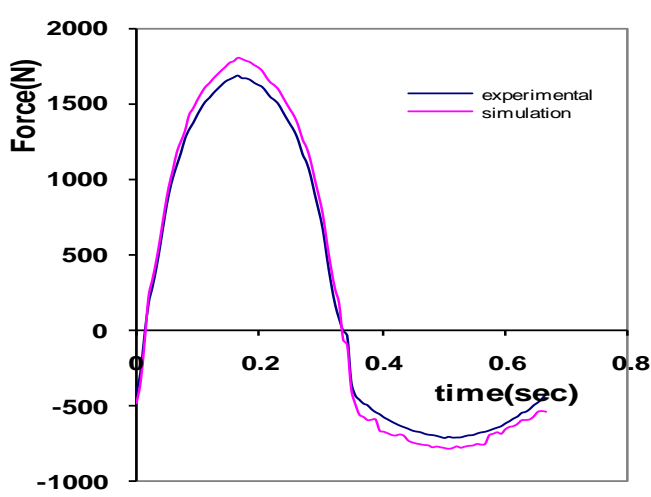

(b)

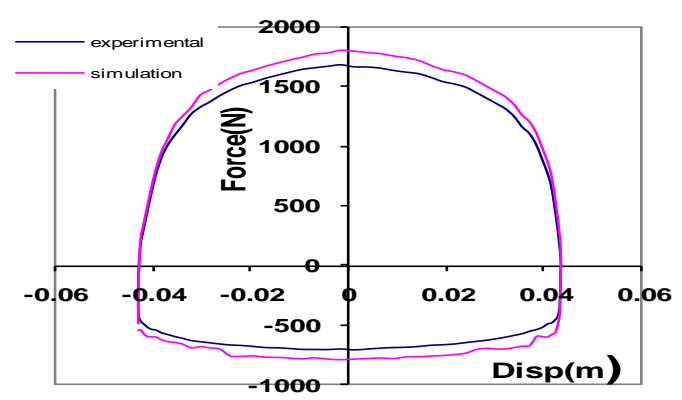

(c)

Figure (8): variation of HSU force with (a) rod velocity, (b) Time, (c) Displacement at frequency $2 \mathrm{~Hz}$ and amplitude $100 \mathrm{~mm}$.

\section{Conclusions:}

(1) The influence of the amplitude and frequency (for low frequency range 0.5 to $4 \mathrm{~Hz}$ ) on the hydro gas suspension unit force is very little so, it can be neglected and the relations between the HSU force and the velocity are non-linear.

(2) The relation between the hydro-gas suspension unit force and the velocity are nonlinear and depend on the design of unit. 
(3) The force of hydro-gas suspension unit is function of the displacements of its lever.

(4) By comparing the experimental results with the numerical simulation results, the numerical simulation can approximately simulate the actual characteristics of the HSU. There is little distortion in simulating results, which may be due to the compressibility of oil not being very accurate introduced. The research on more accurate mathematical model of the HSU will be included in a future work.

\section{References:}

[1] Printed lecture of tanks department, Theory of suspension, chair of tanks, M.T.C., Cairo, Egypt.

[2] Printed lecture of tanks department, Construction of Tracked Vehicles, part II, chair of tanks, M.T.C, Cairo, Egypt, 1995.

[3] Spectral simulation and shock absorber identification, W.Schiehlen \& B.Hu.

[4] Janes's armored and artillery upgrades, twelfth edition (1999-2000), ISBN.

[5] Mathematical modeling of a hydro-gas suspension unit for tracked military vehicle, David J. Purdy and J. Rajesh Kumar.

[6] Experimental and mathematical evaluation of dynamic behavior of an oil-air coupling shock absorber, Y. Ping.

\section{Nomenclature}

$\begin{array}{ll}\text { Ao } & \text { area of orifice, } \mathrm{m}^{2} \\ \mathrm{Af} & \text { area of floating piston, } \mathrm{m}^{2} \\ \mathrm{Ap} & \text { area of the piston, } \mathrm{m}^{2} \\ \mathrm{Ar} & \text { area of rod, } \mathrm{m}^{2} \\ \beta & \text { Bulk's modulus Of oil, } \mathrm{Pa} \\ \mathrm{Cd} & \text { discharge coefficient } \\ \mathrm{C}_{\mathrm{v}} & \text { viscous friction coefficient for the piston, } \mathrm{Ns} / \mathrm{m} \\ \mathrm{ff} & \text { viscous friction coefficient for the floating piston, } \mathrm{Ns} / \mathrm{m} \\ \mathrm{mf} & \text { mass of floating piston, } \mathrm{kg} \\ \mathrm{mp} & \text { mass of piston, } \mathrm{kg} \\ \mathrm{Q} & \text { flow rate of oil through the orifices, } \mathrm{m}^{3} / \mathrm{s} \\ \mathrm{P} 1 & \text { pressure in the lower fluid chamber, pa } \\ \mathrm{P} 2 & \text { pressure in the upper fluid chamber, pa } \\ \mathrm{Pg} & \text { nitrogen gas pressure in the nitrogen chamber, pa } \\ \mathrm{Po} & \text { initial pressure of nitrogen gas in nitrogen chamber, pa } \\ \mathrm{V} 1 & \text { volume of lower chamber, } \mathrm{m}^{3} \\ \mathrm{~V} 2 & \text { volume of upper chamber, } \mathrm{m}^{3} \\ \mathrm{Vo} & \text { initial volume of nitrogen chamber, } \mathrm{m}^{3} \\ \mathrm{Vg} & \text { volume of nitrogen in nitrogen chamber, } \mathrm{m}^{3} \\ \mathrm{X} & \text { displacement of floating piston, } \mathrm{m} \\ \mathrm{Z} & \text { displacement of the rod, } \mathrm{m} \\ \mathrm{HSU} & \text { Hydro gas Suspension Unit }\end{array}$

